\title{
Mechanisms of atrial fibrillation
}

Review article for Heart

Dr Rohan S. Wijesurendra MB BChir MA (Cantab) DPhil MRCP

Professor Barbara Casadei MD DPhil FRCP FMedSci

Division of Cardiovascular Medicine

Radcliffe Department of Medicine

University of Oxford

Level 6 West Wing

John Radcliffe Hospital

Oxford

OX3 9DU

UK

Authors for Correspondence:

Professor Barbara Casadei \& Dr Rohan S. Wijesurendra

T: +44 1865234664

E: barbara.casadei@cardiov.ox.ac.uk; rohan.wijesurendra@cardiov.ox.ac.uk

Manuscript Word Count: 3614

1 Tables/Figures: 5

2 References: 70

3 The Corresponding Authors have the right to grant on behalf of all authors and do grant on behalf 4 of all authors, an exclusive licence on a worldwide basis to the BMJ Publishing Group Ltd and its

5 Licensees to permit this article (if accepted) to be published in HEART editions and any other

6 BMJPGL products to exploit all subsidiary rights.

7 Competing interests

8 RSW has received a speaker fee/honorarium and travel assistance from Biosense Webster and

9 Bayer, and meeting sponsorship/travel assistance from Boston Scientific, Abbott, and Sanofi. BC has

10 no competing interests to declare. 
2

Atrial fibrillation (AF) is the most common sustained arrhythmia, currently affecting over 33 million individuals worldwide ${ }^{1}$. The frequency of $A F$ is closely related to advancing age and its prevalence is expected to more than double over the next 40 years, partly due to changes in population demographics ${ }^{2}$. AF is associated with a two-fold increase in premature mortality ${ }^{3}$, and important major adverse cardiovascular events such as heart failure ${ }^{4}$, severe stroke $\mathrm{e}^{5}$, and myocardial infarction ${ }^{6}$.

Significant effort has been made over a number of years to define the underlying cellular, molecular, and electrophysiological changes that predispose to the induction and maintenance of $A F$ in patients ${ }^{7}$. Progress has been limited by the realisation that AF is a complex arrhythmia that can be the end result of various different pathophysiological processes, with significant heterogeneity between individual patients (and between species) ${ }^{7}$.

In this focused Review article, we aim to succinctly summarise for the non-specialist the current state of knowledge regarding the mechanisms of AF. We address all aspects of pathophysiology, including the basic electrophysiological and structural changes within the left atrium, the genetics of $\mathrm{AF}$, and the links to comorbidities and wider systemic and metabolic perturbations that may be upstream contributors to development of AF. Finally, we outline the translational implications for current and future rhythm control strategies in patients with AF.

\section{Key concepts: trigger and substrate}

AF is characterised and defined by very rapid and uncoordinated atrial activity. Conceptually, the initiation and maintenance of $A F$ can be linked to the interaction between a trigger and the substrate. A "trigger" is a rapidly firing focus that can act as an initiator for the arrhythmia, the maintenance of which generally requires a "substrate", that is, electrophysiological, mechanical, and anatomical characteristics of the atria that sustain AF. Development of this substrate usually includes both electrical and structural elements of atrial remodelling. Electrical remodelling encompasses changes in the properties of ion channels affecting atrial myocardial activation and conduction, whilst structural remodelling refers to alterations in the tissue architecture, both microscopic (e.g. fibrosis) and macroscopic (e.g. atrial dilatation). This conceptual framework for the key concepts underlying the induction and maintenance of $A F$ is summarised in Figure 1.

It is thought that there is a progression over time from a trigger-driven disease, through development of a functional atrial substrate, followed by predominant structural atrial remodelling . $^{\text {. }}$ This would correspond to the clinical observation that AF is often initially paroxysmal, before progressing to a persistent and ultimately permanent form of arrhythmia (Figure 2).

\section{Basic atrial electrophysiology}

In health, atrial cell depolarisation is mediated by a large and rapidly activating and deactivating inward $\mathrm{Na}^{+}$current, and the slower L-type $\mathrm{Ca}^{2+}$ current. Repolarisation is also rapid due to activation 
of a series of voltage-gated $\mathrm{K}^{+}$channels. Action potential duration and refractory period are shorter in the atria (particularly in the left atrium) compared to the ventricular myocardium, although there is significant regional heterogeneity within and between the atria, reflecting systematic differences in intra-atrial ion channel density ${ }^{9}$. Overall, the atrial myocardium is more prone to the development of very rapid rates with complex patterns of conduction than the ventricular myocardium, even before considering the pro-arrhythmic effects of atrial remodelling.

\section{Triggers for $\mathrm{AF}$}

9 Seminal studies by Haisaguerre et al. identified the muscular sleeves within the pulmonary vein (PV) ostia as the source of the ectopic beats triggering $A F$ in many patients with paroxysmal $A F^{10}$. The myocardial sleeves within PVs appear to demonstrate key differences from the remaining atrial myocardium in terms of cellular electrophysiology ${ }^{11}$, gross anatomy, and fibre geometry; these changes appear to predispose the PV muscle sleeves to rapid focal firing or re-entrant activation ${ }^{12}$. It follows that electrical isolation of the PVs from the rest of the atrium (termed "PV isolation") is the cornerstone of catheter ablation of AF.

Non-PV triggers have also been described ${ }^{13,14}$, including (amongst others) the superior vena cava, coronary sinus, left atrial appendage, ligament of Marshall, crista terminalis, and left atrial posterior free wall, potentially due to the presence of myocardial sleeves or regional atrial fibrosis at these sites. Non-PV triggers are more common in advanced subtypes of AF and in patients who have already undergone a catheter ablation procedure. Ablation targeting non-PV triggers may be a useful addition to therapeutic approaches in selected individuals ${ }^{13,15}$. Similarly, ganglionated plexi, which are conglomerations of autonomic ganglia on the epicardial surface of the heart, may play a role in the initiation and maintenance of $\mathrm{AF}^{16}$. Ablation of these plexi in addition to $\mathrm{PV}$ isolation led to improved freedom from atrial tachyarrhythmia compared to PV isolation alone in one small clinical trial ${ }^{17}$. Finally, AF may occasionally also be triggered by other forms of supraventricular arrhythmia, such as atrioventricular nodal re-entrant tachycardia (AVNRT), atrioventricular re-entrant tachycardia (AVRT), and typical counter-clockwise right atrial flutter.

These triggers for AF are themselves often initiated or maintained by "upstream" processes including atrial stretch, ischaemia, and autonomic imbalance. This could explain, at least in part, the clinical observation that $A F$ is more common in conjunction with comorbidities predisposing to these processes, such as mitral regurgitation, myocardial infarction, and vagal stimulation, respectively.

\section{Arrhythmic mechanisms that sustain AF}

In the early days of investigation of the pathophysiology of AF, macro re-entrant circuits were suspected to be the predominant electrophysiological mechanism by key clinical scientists such as Sir Thomas Lewis ${ }^{18}$, but in vivo evidence was lacking. In 1959, Moe and Abildskov extended the idea of re-entry to that of "multiple wavelets" - i.e. the presence of multiple simultaneous re-entrant circuits within the atria ${ }^{19}$. Subsequent work provided mapping evidence of multiple re-entrant 
sustained re-entry by compartmentalising the atrium into small and electrically-isolated units. Unlike classic re-entrant circuits that rely on a central anatomic barrier or scar, so-called "leading circle" reentry in $\mathrm{AF}$ is thought to be functional, due to constant centripetal activation of the centre of the circuit resulting in continuous local refractoriness.

5 There remains a degree of controversy and uncertainty regarding the precise mechanisms that initiate and sustain AF. Some investigators have described "rotors" or spiral waves as a special form of functional re-entry ${ }^{21}$. In a rotor, the wavefront has a curved or spiral form, with the velocity of any specific portion of the wavefront depending on its degree of curvature. The area of wavefront with the highest curvature has the slowest conduction velocity; this results in functional block at the centre of the rotor due to the propagating wavefront being unable to invade this core of tissue. Critically, this means that rotors can meander through space as there is no area of truly refractory myocardium, in contrast to leading circle re-entry, which must remain fixed around the unexcitable centre. Mapping studies have shown that stable rotors can also anchor at certain sites (often around the PVs and in areas of heterogeneous atrial tissue) - wavefronts spreading away from the centre of the rotor then fragment, inducing chaotic and fibrillatory activity within the rest of the atrium ${ }^{22}$. The current hypotheses for AF maintenance are summarised in Figure 3, which illustrates how rotors may be compatible with the ectopic foci and multiple wavelets. This illustration of circuits that can involve the epicardial and mid-myocardial layers also highlights the significant challenges to invasive mapping and identification of rotors, since conventional electroanatomic mapping only directly interrogates the endocardial layer.

Notwithstanding this evidence of complex re-entrant mechanisms involving large areas of atrial myocardium, AF may in some cases also be driven by a rapid localised source of triggered discharge or micro re-entry. In this situation, the remainder of the atrial myocardium may be a bystander as suggested by a study demonstrating that ablation of these so-called driver domains terminated persistent AF in many cases, particular in patients where AF had been persistent for less than 6 months ${ }^{23}$.

Overall, although AF is defined by the presence of chaotic atrial electrical activity, it is now recognised that the pro-arrhythmic mechanisms are extremely heterogeneous. The relative contributions of potential mechanisms appear to be widely variable between different individuals, and may also change over time within a single individual.

\section{Development of a substrate for AF}

The maintenance of $\mathrm{AF}$ is thought to reflect development of a vulnerable substrate as a result of electrical and structural remodelling, particularly within the left atrium. Aspects of atrial electrical remodelling include shortening of the refractory period due to downregulation of the $\mathrm{Ca}^{2+}$ current $^{24}$, accelerated repolarisation and hyperpolarization of atrial cells due to increases in outward $\mathrm{K}^{+}$ currents ${ }^{25}$, and conduction abnormalities due to altered expression and localisation of connexins that connect atrial myocytes ${ }^{26}$. These changes all promote re-entry and chaotic patterns of atrial activation, and are closely related to autonomic nervous activity ${ }^{27}$. 
The most prominent aspects of structural remodelling include progressive atrial dilatation, readily detected by transthoracic echocardiography ${ }^{28}$. Atrial dilatation may support re-entry directly, but is also strongly correlated to the presence of fibrosis ${ }^{29}$. Fibrosis appears to be of critical mechanistic importance to the development and maintenance of $A F$, by causing heterogeneity of electrical conduction and predisposing to re-entry. Atrial fibrosis results from activation of fibroblasts, and has classically been ascribed to ageing, comorbidities and risk factors, although experimental evidence for these assertions is somewhat lacking ${ }^{29}$. In contrast, both animal studies ${ }^{30}$ and post-mortem histological studies in humans ${ }^{29}$ support an association between AF and progressive atrial fibrosis leading to the notion that " $\mathrm{AF}$ begets $\mathrm{AF}$ ", i.e. that $\mathrm{AF}$ directly induces atrial remodelling that supports the further induction and maintenance of AF. This concept appears to tie in with the clinical observation that $\mathrm{AF}$ often progresses from infrequent paroxysms to more frequent and long-lasting episodes, and then persistent $A F$, although an alternative possibility is continuous evolution of the atrial phenotype over time, largely independent of the presence or absence of AF. Meanwhile, progressive structural atrial abnormalities have also been described in the absence of AF, suggesting an alternative paradigm where fibrotic atrial cardiomyopathy is, at least in some patients, an independent disease process that occurs first and predisposes to the subsequent development of arrhythmia ${ }^{31}$.

Cardiac magnetic resonance now offers the possibility of accurate, non-invasive, and serial atrial imaging ${ }^{32}$, including assessment of atrial tissue characteristics with atrial late gadolinium enhancement imaging (Figure 4) ${ }^{33}$. Atrial late gadolinium enhancement is thought to reflect the presence of atrial fibrosis, although this is largely based on correlation with invasive electroanatomic data $^{34}$ and studies of post-ablation atrial injury in animals ${ }^{35}$, rather than histological validation in patients. Nevertheless, these advanced imaging approaches should in time increase our understanding of the predictors, natural history, and clinical significance of atrial remodelling. Already, such studies have shown that patients with stroke of undetermined cause have more atrial late gadolinium enhancement than patients with an identified non-AF related specific cause of stroke, suggesting a possible aetiological role for an underlying atrial cardiomyopathy without clinical evidence of $\mathrm{AF}^{36}$. Meanwhile, the multicentre DECAAF trial demonstrated that atrial late gadolinium enhancement was independently associated with likelihood of recurrent arrhythmia after catheter ablation of $\mathrm{AF}^{37}$. Thus, increasing evidence suggests that atrial fibrosis may be an important marker of disease severity and predictor of clinical outcomes. However, it remains unclear whether atrial fibrosis is a potentially modifiable risk factor - this hypothesis is being tested in the ongoing DECAAF II trial (NCT02529319), which will test the efficacy of fibrosis-guided ablation in addition to conventional PV isolation.

\section{Alterations in myocardial redox state in atrial remodelling and AF}

More recent efforts have focused on identifying the underlying cellular and molecular mechanisms that lead to atrial remodelling. Alterations in myocyte nitroso-redox state have been closely linked to the initiation, development, and maintenance of $\mathrm{AF}^{38}$. Redox signalling can affect downstream targets in various subcellular compartments via effects on transcription factors, direct protein transnitrosylation, or targeting of other signalling molecules. For example, angiotensin-II-induced oxidation of $\mathrm{Ca}^{2+} /$ calmodulin-dependent protein kinase 2 (CaMKII) results in increased sarcoplasmic 
1 reticulum $\mathrm{Ca}^{2+}$ leak through the ryanodine receptor, and contributes directly to increased

2 susceptibility to AF in mice ${ }^{39}$.

3 Alterations in redox signalling in AF are complex, and the atrial sources of reactive oxygen species 4 have been shown to differ with the duration and substrate of $A F^{40}$. Recent work has identified that 5 atrial specific up-regulation of a small noncoding RNA (miR-31) leads to depletion of neuronal nitric oxide synthase and repression of dystrophin (which binds neuronal nitric oxide synthase in the myocardium $)^{41}$. The disruption in neuronal nitric oxide signalling leads to shorter action potential duration and loss of rate-dependent adaptation in action potential duration, creating a proarrhythmic substrate ${ }^{41}$. This suggests that local inhibition of relevant miRs in the atrial myocardium could reverse atrial remodelling and potentially act as a novel adjunct to current therapeutic strategies, assuming that tissue-specific delivery strategies can be developed.

\section{Genetics of AF}

Individuals with a family member affected by AF have a $40 \%$ greater risk of incident AF than those without an affected family member, after adjusting for AF risk factors ${ }^{42}$. Genome-wide association studies have progressively identified more risk variants and genes that underlie the observation of familial risk, enriched within cardiac developmental, electrophysiological, contractile, and structural pathways ${ }^{43}$. A recent such study of over 1 million individuals identified 142 independent risk variants at 111 loci, corresponding to 151 gene candidates likely to be involved in AF pathogenesis ${ }^{44}$. Pathway and functional enrichment analyses have further highlighted foetal heart tissue and pathways related to cardiac development as being functionally relevant in AF pathogenesis, implying that such genes and pathways either act in the developing heart to influence the future risk of AF, or that they are activated in the adult heart as a response to stress ${ }^{44}$.

The genes and pathways identified from such approaches may allow new insights into AF pathophysiology, and potentially reveal new therapeutic targets. Whilst genetic testing is not currently undertaken routinely in patients with AF, this could change rapidly if polygenic risk scores can be identified that, for example, contribute to the clinical classification of AF phenotype, aid stroke risk stratification, or predict response to catheter ablation.

As detailed above, several decades of detailed investigation have yielded fundamental insights into the pathophysiology of AF and the associated alterations in the cellular, molecular, electrophysiological and structural architecture of the atria. More recently, it has become increasingly recognised that $A F$ is more than just an atrial disease, with documented associations with systemic inflammation, endothelial dysfunction, cardiometabolic disturbance, and wider abnormalities in myocardial structure and function ${ }^{45}$.

Longitudinal and multiparametric cardiac magnetic resonance studies show that even patients with apparently lone AF have significantly impaired ventricular myocardial energetics (Figure 5), coronary 
normalise following catheter ablation ${ }^{32,46}$. This suggests that AF may actually be the consequence (rather than the cause) of an occult cardiomyopathy, which is unaffected by successful rhythm control, and that adjunctive therapies may be needed to target the ongoing drivers of the disease process.

These observations are also in keeping with the strong epidemiological associations between AF and other cardiac, metabolic, and systemic comorbidity ${ }^{47}$. An exemplar is obesity, which is the strongest modifiable risk factor for $\mathrm{AF}^{48}$, with a Mendelian randomisation study indicating a direct causal relationship ${ }^{49,50}$. Further evidence for the clinical relevance of obesity and other systemic diseases in AF comes from emerging randomised and cohort studies demonstrating dramatic improvements in AF burden and symptoms following weight loss and risk factor control ${ }^{51-53}$. The mechanism by which obesity predisposes to $A F$ is unclear, but much interest has focused on the potential role of epicardial fat, which is closely associated with AF phenotype and recurrence. A body of work indicates that epicardial fat may influence the triggers and substrate for AF through a number of mechanisms, including fatty infiltration of the atrial myocardium, induction of atrial fibrosis, and activation of inflammatory and oxidative stress pathways $s^{54,55}$. Other potential mechanisms include left atrial enlargement, left ventricular hypertrophy ${ }^{56}$, and altered cardiac energetics ${ }^{57}$.

Finally, the intriguing possibility that AF progression is linked to vascular risk via hypercoagulability that influences atrial vascular remodelling and fibrosis is being assessed in the ongoing RACE-V cohort study (NCT02726698).

\section{Implications for current and future rhythm control strategies}

Progressive advances in our knowledge of the mechanisms of AF have directly translated into current rhythm control strategies, both pharmacological and interventional. It is important to emphasise that rhythm control strategies have generally not demonstrated any prognostic benefit compared to rate control strategies in patients with $\mathrm{AF}^{58,59}$. Similarly, the recently published CABANA trial failed to demonstrate an improvement in the composite outcome of mortality, stroke, bleeding, and cardiac arrest in patients randomised to pulmonary vein isolation via catheter ablation compared to those randomised to rate and rhythm control with medical therapy, despite a significant reduction in recurrent $\mathrm{AF}$ in the former group ${ }^{60}$. Catheter ablation remains commonly indicated solely for the improvement of symptoms ${ }^{61-63}$, although evidence for improvement in symptoms and/or quality of life derives from open-label studies including CABANA ${ }^{62}$, where the mean differences in quality of life and symptom scores between the groups at 12 months were of questionable clinical significance, particularly given the possibility of a larger placebo effect resulting from an interventional therapy. Definitive evidence of symptomatic benefit from ablation would require more rigorous blinded comparisons of ablation with a sham procedure, and such trials are currently lacking.

Meanwhile, the recent and relatively small CASTLE-AF randomised trial also demonstrated a significant improvement in the composite primary endpoint of mortality and the rate of hospitalisation for worsening heart failure with ablation compared to medical therapy, suggesting prognostic benefit of ablation in selected patients with AF and heart failure ${ }^{64}$. These data are consistent with the results of prior smaller randomised trials comparing catheter ablation versus 
medical therapy in patients with AF and heart failure ${ }^{65}$, and a trend towards benefit of catheter ablation compared to medical therapy in patients with a history of congestive heart failure or NYHA II-IV symptoms in CABANA ${ }^{60}$. Meanwhile, the soon-to-report EAST trial (NCT01288352) has been designed to test the hypothesis that early and structured rhythm control therapy (with antiarrhythmic drugs and catheter ablation) can prevent AF-related complications compared to usual care in a less selected group of AF patients.

Pharmaceutical approaches with anti-arrhythmic drugs are targeted to reverse the effects of atrial electrical remodelling, mainly by prolonging the atrial effective refractory period and lengthening atrial action potential duration, thereby reducing the propensity for induction and maintenance of AF. Although theoretically potentially pro-arrhythmic, these medications are relatively safe in clinical use, with an incidence of major ventricular arrhythmia of just $0.8 \%$ over the median 4 -year follow-up in CABANA ${ }^{60}$. Nevertheless, side-effects remain a limiting factor to the long-term acceptability of such medications at therapeutic doses for many individuals.

Over the last two decades, catheter ablation has become a mainstream rhythm control strategy, established in clinical guidelines ${ }^{61}$. PV isolation is the mainstay of catheter ablation, and can be used as a first line treatment in patients with paroxysmal $A F$, in whom it is at least as effective as antiarrhythmic drug therapy ${ }^{61}$. Persistent AF is much more challenging, as no approach to atrial substrate modification with ablation has proven effective. In the pivotal STAR AF II trial, patients were randomised in a 1:4:4 ratio to ablation with PV isolation alone, $\mathrm{PV}$ isolation plus ablation of electrograms showing complex fractionated activity, or PV isolation plus additional linear ablation across the left atrial roof and mitral valve isthmus. The results were sobering: around $40 \%$ of patients experienced recurrent $A F$ after ablation with no statistically significant differences between the groups, although there was a trend to more recurrent AF in both groups who received additional ablation compared to those treated with PV isolation alone ${ }^{66}$. Further work is therefore still needed to understand if, and how, the atrial substrate for AF can be ameliorated by ablation. In this context, the results of the recent RACE 3 trial are also particularly relevant ${ }^{67}$. Patients with early persistent AF and mild-to-moderate heart failure randomised to targeted therapy of underlying conditions (consisting of both pharmacological and lifestyle interventions) had improved maintenance of sinus rhythm at 1 year compared to those randomised to conventional therapy ${ }^{67}$. Similarly, weight loss ${ }^{51}$ and improvement in cardiorespiratory fitness ${ }^{68}$ appear to be associated with a reduction in AF burden and symptom severity. This supports the paradigm that more holistic therapy, beyond catheter ablation alone, is likely to be required for the successful treatment of persistent AF.

\section{Summary and conclusions}

AF is a complex arrhythmia that is characterised and defined by rapid and uncoordinated atrial activity. The pattern of atrial electrical activity in AF is not completely understood, but can include complex re-entrant mechanisms as well as localised focal discharges and micro re-entry. The initiation and maintenance of $\mathrm{AF}$ is dependent on the presence of both trigger and substrate, including electrical and structural atrial remodelling. Paroxysmal AF often precedes persistent AF, consistent with experimental evidence showing that $A F$ can itself induce atrial remodelling that contributes to the further maintenance of AF. 
1 Atrial remodelling and $\mathrm{AF}$ often reflect the combined effects of several discrete and interacting

2 pathophysiological processes, both inherited and acquired, although there is significant

3 heterogeneity in the balance of the contributions of each of these mechanisms in any one individual.

4 AF is closely associated with advanced age, the presence of comorbidities and systemic disease,

5 cardiometabolic disturbance, and wider abnormalities in myocardial structure and function,

6 consistent with a pathophysiological basis that goes beyond the atrial myocardium, although the

7 precise mechanisms linking extra-atrial pathology to AF remain poorly defined.

8 Pharmacological and interventional therapeutic approaches to rhythm control in AF mainly address

9 alterations in atrial electrophysiology and triggers for AF. The limitations of current approaches are

10 particularly pronounced in patients with persistent AF and/or advanced structural atrial remodelling.

11 Further mechanistic, translational, and clinical studies are needed to improve understanding of AF

12 mechanisms and pathophysiology, and direct development of novel therapeutic approaches. 


\section{Figure 1: Key concepts underlying the induction and maintenance of AF}

3

4

5

6

7

8

Figure 1. Key concepts underlying the induction and maintenance of atrial fibrillation (AF). AF can be maintained by either re-entrant or rapid and sustained ectopic activity. Development of re-entry depends on the action of a trigger (usually from an ectopic beat) acting on vulnerable substrate. In normal hearts, atrial electrical properties are less likely to support the maintenance of AF. Atrial remodelling creates a substrate for re-entrant $A F$, by altering ion-channel function and/or inducing tissue fibrosis. Remodelling can also make ectopic activity more likely by producing changes in $\mathrm{Ca}^{2+}-$ handling that promote both triggered activity and re-entry. EADs indicates early afterdepolarisations; DADs, delayed afterdepolarisations. Reproduced with permission from ref. ${ }^{69}$

\section{Figure 2: Progression in AF mechanisms over time}

Figure 2. Progression in atrial fibrillation (AF) mechanisms over time. A, Local ectopic firing. B, Singlecircuit re-entry. C, Multiple-circuit re-entry. D, Mechanisms underlying clinical forms of AF. Paroxysmal $A F$ is mostly underpinned by local triggers/drivers, particularly from pulmonary veins (PVs). As AF becomes more persistent and eventually permanent, re-entry substrates (initially functional and then structural) predominate. RA indicates right atrium; SVC, superior vena cava; LA, left atrium; and IVC, inferior vena cava. Reproduced with permission from ref. ${ }^{8}$

\section{Figure 3: Current hypotheses for AF maintenance}

Figure 3. Current hypotheses for AF maintenance. (A) Diagram of AF maintenance near a pulmonary vein that has been hypothesized to be driven by ectopic focus (left), rotor (middle), or multiple wavelets (right). Different wavefronts are represented in purple. (B) Representation of the compatibility of rotor maintenance with other mechanisms. Rotors can be initiated by wavebreaks near an ectopic focus (left) and underlie endocardial or epicardial breakthroughs (middle). A drifting rotor, whose trajectory is depicted in blue, can be the driver of multiple and apparently disorganized atrial wavelets (right). Reproduced with permission from ref. ${ }^{21}$

\section{Figure 4: Left atrial tissue characterisation using late gadolinium enhancement magnetic resonance imaging}

Figure 4. Left atrial tissue characterisation using late gadolinium enhancement (LGE) magnetic resonance imaging (MRI). Following acquisition of high-resolution LGE-MRI scans (step 1), the left atrial wall is identified and isolated by manually tracing the blood pool in each slice of the LGE-MRI volume (step 2). The mitral valve and extension of the left ventricle are manually excluded. Quantification of fibrosis is based on the relative signal intensity of LGE (step 3). A 3-dimensional model of the LA is rendered with the maximum enhancement intensities being projected on the 
model surface; healthy tissue is depicted as blue, whereas any tissue with LGE is depicted as green and yellow (step 4). Reproduced with permission from ref. ${ }^{33}$

\section{Figure 5: Left ventricular energetics in patients with lone atrial fibrillation}

Figure 5. Left ventricular energetics in patients with lone atrial fibrillation (AF). The ${ }^{31} \mathrm{P}$ magnetic resonance spectra and derived PCr/ATP ratios are shown in a control subject ( $A$, top panel) and a patient with lone $A F$ before catheter ablation ( $A$, bottom panel). Despite a significant reduction in $A F$ burden at a median of 7 months after ablation $(p<0.001)(B)$, there was no change in PCr/ATP ratio $(p=0.57)$ ( $C$, left panel), with myocardial energetics remaining significantly impaired compared with matched control subjects in sinus rhythm $(p=0.001)(C$, right panel). 2,3-DPG indicates 2,3diphosphoglycerate; $\mathrm{AF}=$ atrial fibrillation; $\mathrm{IQR}=$ interquartile range; $\mathrm{PCr} / \mathrm{ATP}=$ phosphocreatine/adenosine triphosphate; $\mathrm{PDE}=$ phosphodiester. Reproduced with permission from ref $^{70}$, originally adapted from ref $^{32}$.

\section{References}

1. Chugh SS, Havmoeller R, Narayanan K, Singh D, Rienstra M, Benjamin EJ, Gillum RF, Kim YH, McAnulty JH, Jr., Zheng ZJ, Forouzanfar MH, Naghavi M, Mensah GA, Ezzati M and Murray CJ. Worldwide epidemiology of atrial fibrillation: a Global Burden of Disease 2010 Study. Circulation. 2014;129:837-47.

2. Krijthe BP, Kunst A, Benjamin EJ, Lip GY, Franco OH, Hofman A, Witteman JC, Stricker BH and Heeringa J. Projections on the number of individuals with atrial fibrillation in the European Union, from 2000 to 2060. European heart journal. 2013;34:2746-51.

3. Benjamin EJ, Wolf PA, D'Agostino RB, Silbershatz H, Kannel WB and Levy D. Impact of atrial fibrillation on the risk of death: the Framingham Heart Study. Circulation. 1998;98:946-52.

4. Vermond RA, Geelhoed B, Verweij N, Tieleman RG, Van der Harst P, Hillege HL, Van Gilst WH, Van Gelder IC and Rienstra M. Incidence of Atrial Fibrillation and Relationship With Cardiovascular Events, Heart Failure, and Mortality: A Community-Based Study From the Netherlands. Journal of the American College of Cardiology. 2015;66:1000-7.

5. Lin HJ, Wolf PA, Kelly-Hayes M, Beiser AS, Kase CS, Benjamin EJ and D'Agostino RB. Stroke severity in atrial fibrillation. The Framingham Study. Stroke; a journal of cerebral circulation. 1996;27:1760-4.

6. Soliman EZ, Safford MM, Muntner P, Khodneva Y, Dawood FZ, Zakai NA, Thacker EL, Judd S, Howard VJ, Howard G, Herrington DM and Cushman M. Atrial fibrillation and the risk of myocardial infarction. JAMA internal medicine. 2014;174:107-14.

7. Schotten $U$, Verheule S, Kirchhof $P$ and Goette A. Pathophysiological mechanisms of atrial fibrillation: a translational appraisal. Physiological reviews. 2011;91:265-325.

8. Iwasaki YK, Nishida K, Kato T and Nattel S. Atrial fibrillation pathophysiology: implications for management. Circulation. 2011;124:2264-74.

9. Li D, Zhang L, Kneller J and Nattel S. Potential ionic mechanism for repolarization differences between canine right and left atrium. Circulation research. 2001;88:1168-75.

10. Haissaguerre M, Jais P, Shah DC, Takahashi A, Hocini M, Quiniou G, Garrigue S, Le Mouroux $A$, Le Metayer $P$ and Clementy J. Spontaneous initiation of atrial fibrillation by ectopic beats originating in the pulmonary veins. The New England journal of medicine. 1998;339:659-66. 
11. Chen SA, Hsieh MH, Tai CT, Tsai CF, Prakash VS, Yu WC, Hsu TL, Ding YA and Chang MS. Initiation of atrial fibrillation by ectopic beats originating from the pulmonary veins: electrophysiological characteristics, pharmacological responses, and effects of radiofrequency ablation. Circulation. 1999;100:1879-86.

12. Khan R. Identifying and understanding the role of pulmonary vein activity in atrial fibrillation. Cardiovascular research. 2004;64:387-94.

13. Santangeli $P$ and Marchlinski FE. Techniques for the provocation, localization, and ablation of non-pulmonary vein triggers for atrial fibrillation. Heart Rhythm. 2017;14:1087-1096.

14. Tsai CF, Tai CT, Hsieh MH, Lin WS, Yu WC, Ueng KC, Ding YA, Chang MS and Chen SA. Initiation of atrial fibrillation by ectopic beats originating from the superior vena cava: electrophysiological characteristics and results of radiofrequency ablation. Circulation. 2000;102:6774. 15. Lin WS, Tai CT, Hsieh MH, Tsai CF, Lin YK, Tsao HM, Huang JL, Yu WC, Yang SP, Ding YA, Chang MS and Chen SA. Catheter ablation of paroxysmal atrial fibrillation initiated by non-pulmonary vein ectopy. Circulation. 2003;107:3176-83.

16. Stavrakis S and Po S. Ganglionated Plexi Ablation: Physiology and Clinical Applications. Arrhythm Electrophysiol Rev. 2017;6:186-190.

17. Katritsis DG, Pokushalov E, Romanov A, Giazitzoglou E, Siontis GC, Po SS, Camm AJ and Ioannidis JP. Autonomic denervation added to pulmonary vein isolation for paroxysmal atrial fibrillation: a randomized clinical trial. Journal of the American College of Cardiology. 2013;62:231825.

18. Lewis T. Oliver-Sharpey Lectures ON THE NATURE OF FLUTTER AND FIBRILLATION OF THE AURICLE. Br Med J. 1921;1:590-3.

19. Moe GK and Abildskov JA. Atrial fibrillation as a self-sustaining arrhythmia independent of focal discharge. American heart journal. 1959;58:59-70.

20. Cox JL, Canavan TE, Schuessler RB, Cain ME, Lindsay BD, Stone C, Smith PK, Corr PB and Boineau JP. The surgical treatment of atrial fibrillation. II. Intraoperative electrophysiologic mapping and description of the electrophysiologic basis of atrial flutter and atrial fibrillation. J Thorac Cardiovasc Surg. 1991;101:406-26.

21. Guillem MS, Climent AM, Rodrigo M, Fernandez-Aviles F, Atienza F and Berenfeld O. Presence and stability of rotors in atrial fibrillation: evidence and therapeutic implications. Cardiovascular research. 2016;109:480-92.

22. Jalife J, Berenfeld $O$ and Mansour M. Mother rotors and fibrillatory conduction: a mechanism of atrial fibrillation. Cardiovascular research. 2002;54:204-16.

23. Haissaguerre $M$, Hocini $M$, Denis $A$, Shah AJ, Komatsu $Y$, Yamashita $S$, Daly $M$, Amraoui $S$, Zellerhoff S, Picat MQ, Quotb A, Jesel L, Lim H, Ploux S, Bordachar P, Attuel G, Meillet V, Ritter P, Derval N, Sacher F, Bernus O, Cochet H, Jais $P$ and Dubois R. Driver Domains in Persistent Atrial Fibrillation. Circulation. 2014.

24. Yue L, Feng J, Gaspo R, Li GR, Wang Z and Nattel S. lonic remodeling underlying action potential changes in a canine model of atrial fibrillation. Circulation research. 1997;81:512-25. 25. Heijman J, Voigt N, Nattel S and Dobrev D. Cellular and molecular electrophysiology of atrial fibrillation initiation, maintenance, and progression. Circulation research. 2014;114:1483-99.

26. Igarashi T, Finet JE, Takeuchi A, Fujino Y, Strom M, Greener ID, Rosenbaum DS and Donahue JK. Connexin gene transfer preserves conduction velocity and prevents atrial fibrillation. Circulation. 2012;125:216-25.

27. Chen PS, Chen LS, Fishbein MC, Lin SF and Nattel S. Role of the autonomic nervous system in atrial fibrillation: pathophysiology and therapy. Circulation research. 2014;114:1500-15.

28. Sanfilippo AJ, Abascal VM, Sheehan M, Oertel LB, Harrigan P, Hughes RA and Weyman AE. Atrial enlargement as a consequence of atrial fibrillation. A prospective echocardiographic study. Circulation. 1990;82:792-7. 
29. Platonov PG, Mitrofanova LB, Orshanskaya V and Ho SY. Structural abnormalities in atrial walls are associated with presence and persistency of atrial fibrillation but not with age. Journal of the American College of Cardiology. 2011;58:2225-32.

30. Wijffels MC, Kirchhof CJ, Dorland R and Allessie MA. Atrial fibrillation begets atrial fibrillation. A study in awake chronically instrumented goats. Circulation. 1995;92:1954-68. 31. Kottkamp H. Human atrial fibrillation substrate: towards a specific fibrotic atrial cardiomyopathy. European heart journal. 2013;34:2731-8.

32. Wijesurendra RS, Liu A, Eichhorn C, Ariga R, Levelt E, Clarke WT, Rodgers CT, Karamitsos TD, Bashir Y, Ginks M, Rajappan K, Betts T, Ferreira VM, Neubauer S and Casadei B. Lone Atrial Fibrillation Is Associated With Impaired Left Ventricular Energetics That Persists Despite Successful Catheter Ablation. Circulation. 2016;134:1068-1081.

33. Siebermair J, Kholmovski EG and Marrouche N. Assessment of Left Atrial Fibrosis by Late Gadolinium Enhancement Magnetic Resonance Imaging: Methodology and Clinical Implications. JACC Clin Electrophysiol. 2017;3:791-802.

34. Malcolme-Lawes LC, Juli C, Karim R, Bai W, Quest R, Lim PB, Jamil-Copley S, Kojodjojo P, Ariff B, Davies DW, Rueckert D, Francis DP, Hunter R, Jones D, Boubertakh R, Petersen SE, Schilling R, Kanagaratnam $P$ and Peters NS. Automated analysis of atrial late gadolinium enhancement imaging that correlates with endocardial voltage and clinical outcomes: A 2-center study. Heart Rhythm. 2013.

35. Harrison JL, Jensen HK, Peel SA, Chiribiri A, Grondal AK, Bloch LO, Pedersen SF, Bentzon JF, Kolbitsch C, Karim R, Williams SE, Linton NW, Rhode KS, Gill J, Cooklin M, Rinaldi CA, Wright M, Kim WY, Schaeffter T, Razavi RS and O'Neill MD. Cardiac magnetic resonance and electroanatomical mapping of acute and chronic atrial ablation injury: a histological validation study. European heart journal. 2014;35:1486-95.

36. Fonseca AC, Alves P, Inacio N, Marto JP, Viana-Baptista M, Pinho EMT, Ferro JM and Almeida AG. Patients With Undetermined Stroke Have Increased Atrial Fibrosis: A Cardiac Magnetic Resonance Imaging Study. Stroke; a journal of cerebral circulation. 2018;49:734-737.

37. Marrouche NF, Wilber D, Hindricks G, Jais P, Akoum N, Marchlinski F, Kholmovski E, Burgon $\mathrm{N}$, Hu N, Mont L, Deneke T, Duytschaever M, Neumann T, Mansour M, Mahnkopf C, Herweg B, Daoud E, Wissner E, Bansmann $\mathrm{P}$ and Brachmann J. Association of atrial tissue fibrosis identified by delayed enhancement MRI and atrial fibrillation catheter ablation: the DECAAF study. JAMA : the journal of the American Medical Association. 2014;311:498-506.

38. Simon JN, Ziberna K and Casadei B. Compromised redox homeostasis, altered nitroso-redox balance, and therapeutic possibilities in atrial fibrillation. Cardiovascular research. 2016;109:510-8. 39. Purohit A, Rokita AG, Guan X, Chen B, Koval OM, Voigt N, Neef S, Sowa T, Gao Z, Luczak ED, Stefansdottir H, Behunin AC, Li N, El-Accaoui RN, Yang B, Swaminathan PD, Weiss RM, Wehrens XH, Song LS, Dobrev D, Maier LS and Anderson ME. Oxidized $\mathrm{Ca}(2+) /$ calmodulin-dependent protein kinase II triggers atrial fibrillation. Circulation. 2013;128:1748-57.

40. Reilly SN, Jayaram R, Nahar K, Antoniades C, Verheule S, Channon KM, Alp NJ, Schotten U and Casadei $B$. Atrial sources of reactive oxygen species vary with the duration and substrate of atrial fibrillation: implications for the antiarrhythmic effect of statins. Circulation. 2011;124:1107-17. 41. Reilly SN, Liu X, Carnicer R, Recalde A, Muszkiewicz A, Jayaram R, Carena MC, Wijesurendra R, Stefanini M, Surdo NC, Lomas O, Ratnatunga C, Sayeed R, Krasopoulos G, Rajakumar T, BuenoOrovio A, Verheule S, Fulga TA, Rodriguez B, Schotten U and Casadei B. Up-regulation of miR-31 in human atrial fibrillation begets the arrhythmia by depleting dystrophin and neuronal nitric oxide synthase. Science translational medicine. 2016;8:340ra74.

42. Lubitz SA, Yin X, Fontes JD, Magnani JW, Rienstra M, Pai M, Villalon ML, Vasan RS, Pencina MJ, Levy D, Larson MG, Ellinor PT and Benjamin EJ. Association between familial atrial fibrillation and risk of new-onset atrial fibrillation. JAMA : the journal of the American Medical Association. 2010;304:2263-9. 
43. Roselli $C$, Chaffin MD, Weng LC, Aeschbacher S, Ahlberg G, Albert CM, Almgren $P$, Alonso $A$, Anderson CD, Aragam KG, Arking DE, Barnard J, Bartz TM, Benjamin EJ, Bihlmeyer NA, Bis JC, Bloom HL, Boerwinkle E, Bottinger EB, Brody JA, Calkins H, Campbell A, Cappola TP, Carlquist J, Chasman DI, Chen LY, Chen YI, Choi EK, Choi SH, Christophersen IE, Chung MK, Cole JW, Conen D, Cook J, Crijns HJ, Cutler MJ, Damrauer SM, Daniels BR, Darbar D, Delgado G, Denny JC, Dichgans M, Dorr M, Dudink EA, Dudley SC, Esa N, Esko T, Eskola M, Fatkin D, Felix SB, Ford I, Franco OH, Geelhoed B, Grewal RP, Gudnason V, Guo X, Gupta N, Gustafsson S, Gutmann R, Hamsten A, Harris TB, Hayward C, Heckbert SR, Hernesniemi J, Hocking LJ, Hofman A, Horimoto A, Huang J, Huang PL, Huffman J, Ingelsson E, Ipek EG, Ito K, Jimenez-Conde J, Johnson R, Jukema JW, Kaab S, Kahonen M, Kamatani Y, Kane JP, Kastrati A, Kathiresan S, Katschnig-Winter P, Kavousi M, Kessler T, Kietselaer BL, Kirchhof P, Kleber ME, Knight S, Krieger JE, Kubo M, Launer LJ, Laurikka J, Lehtimaki T, Leineweber K, Lemaitre RN, Li M, Lim HE, Lin HJ, Lin H, Lind L, Lindgren CM, Lokki ML, London B, Loos RJF, Low SK, Lu Y, Lyytikainen LP, Macfarlane PW, Magnusson PK, Mahajan A, Malik R, Mansur AJ, Marcus GM, Margolin L, Margulies KB, Marz W, McManus DD, Melander O, Mohanty S, Montgomery JA, Morley MP, Morris AP, MullerNurasyid M, Natale A, Nazarian S, Neumann B, Newton-Cheh C, Niemeijer MN, Nikus K, Nilsson P, Noordam R, Oellers H, Olesen MS, Orho-Melander M, Padmanabhan S, Pak HN, Pare G, Pedersen NL, Pera J, Pereira A, Porteous D, Psaty BM, Pulit SL, Pullinger CR, Rader DJ, Refsgaard L, Ribases M, Ridker PM, Rienstra M, Risch L, Roden DM, Rosand J, Rosenberg MA, Rost N, Rotter JI, Saba S, Sandhu RK, Schnabel RB, Schramm K, Schunkert H, Schurman C, Scott SA, Seppala I, Shaffer C, Shah $S$, Shalaby AA, Shim J, Shoemaker MB, Siland JE, Sinisalo J, Sinner MF, Slowik A, Smith AV, Smith BH, Smith JG, Smith JD, Smith NL, Soliman EZ, Sotoodehnia N, Stricker BH, Sun A, Sun H, Svendsen JH, Tanaka T, Tanriverdi K, Taylor KD, Teder-Laving M, Teumer A, Theriault S, Trompet S, Tucker NR, Tveit A, Uitterlinden AG, Van Der Harst P, Van Gelder IC, Van Wagoner DR, Verweij N, Vlachopoulou E, Volker U, Wang B, Weeke PE, Weijs B, Weiss R, Weiss S, Wells QS, Wiggins KL, Wong JA, Woo D, Worrall BB, Yang PS, Yao J, Yoneda ZT, Zeller T, Zeng L, Lubitz SA, Lunetta KL and Ellinor PT. Multiethnic genome-wide association study for atrial fibrillation. Nat Genet. 2018;50:1225-1233. 44. Nielsen JB, Thorolfsdottir RB, Fritsche LG, Zhou W, Skov MW, Graham SE, Herron TJ, McCarthy S, Schmidt EM, Sveinbjornsson G, Surakka I, Mathis MR, Yamazaki M, Crawford RD, Gabrielsen ME, Skogholt AH, Holmen OL, Lin M, Wolford BN, Dey R, Dalen H, Sulem P, Chung JH, Backman JD, Arnar DO, Thorsteinsdottir U, Baras A, O'Dushlaine C, Holst AG, Wen X, Hornsby W, Dewey FE, Boehnke M, Kheterpal S, Mukherjee B, Lee S, Kang HM, Holm H, Kitzman J, Shavit JA, Jalife J, Brummett CM, Teslovich TM, Carey DJ, Gudbjartsson DF, Stefansson K, Abecasis GR, Hveem K and Willer CJ. Biobank-driven genomic discovery yields new insight into atrial fibrillation biology. Nat Genet. 2018;50:1234-1239.

45. Wijesurendra RS and Casadei B. Atrial fibrillation: effects beyond the atrium? Cardiovascular research. 2015;105:238-47.

46. Wijesurendra RS, Liu A, Notaristefano F, Ntusi NAB, Karamitsos TD, Bashir Y, Ginks M, Rajappan K, Betts TR, Jerosch-Herold M, Ferreira VM, Neubauer S and Casadei B. Myocardial Perfusion Is Impaired and Relates to Cardiac Dysfunction in Patients With Atrial Fibrillation Both Before and After Successful Catheter Ablation. J Am Heart Assoc. 2018;7:e009218.

47. Ball J, Carrington MJ, McMurray JJ and Stewart S. Atrial fibrillation: profile and burden of an evolving epidemic in the 21st century. International journal of cardiology. 2013;167:1807-24.

48. Magnussen C, Niiranen TJ, Ojeda FM, Gianfagna F, Blankenberg S, Njolstad I, Vartiainen E, Sans S, Pasterkamp G, Hughes M, Costanzo S, Donati MB, Jousilahti P, Linneberg A, Palosaari T, de Gaetano G, Bobak M, den Ruijter HM, Mathiesen E, Jorgensen T, Soderberg S, Kuulasmaa K, Zeller T, lacoviello L, Salomaa V, Schnabel RB and BiomarCa REC. Sex Differences and Similarities in Atrial Fibrillation Epidemiology, Risk Factors, and Mortality in Community Cohorts: Results From the BiomarCaRE Consortium (Biomarker for Cardiovascular Risk Assessment in Europe). Circulation. 2017;136:1588-1597.

49. Chatterjee NA, Giulianini F, Geelhoed B, Lunetta KL, Misialek JR, Niemeijer MN, Rienstra M, Rose LM, Smith AV, Arking DE, Ellinor PT, Heeringa J, Lin H, Lubitz SA, Soliman EZ, Verweij N, Alonso 
A, Benjamin EJ, Gudnason V, Stricker BHC, Van Der Harst P, Chasman DI and Albert CM. Genetic Obesity and the Risk of Atrial Fibrillation: Causal Estimates from Mendelian Randomization. Circulation. 2017;135:741-754.

50. Tikkanen E, Gustafsson S, Knowles JW, Perez M, Burgess S and Ingelsson E. Body composition and atrial fibrillation: a Mendelian randomization study. European heart journal. 2019;40:1277-1282.

51. Abed HS, Wittert GA, Leong DP, Shirazi MG, Bahrami B, Middeldorp ME, Lorimer MF, Lau DH, Antic NA, Brooks AG, Abhayaratna WP, Kalman JM and Sanders P. Effect of weight reduction and cardiometabolic risk factor management on symptom burden and severity in patients with atrial fibrillation: a randomized clinical trial. JAMA : the journal of the American Medical Association. 2013;310:2050-60.

52. Pathak RK, Middeldorp ME, Lau DH, Mehta AB, Mahajan R, Twomey D, Alasady M, Hanley L, Antic NA, McEvoy RD, Kalman JM, Abhayaratna WP and Sanders P. Aggressive Risk Factor Reduction Study for Atrial Fibrillation and Implications for the Outcome of Ablation: The ARREST-AF Cohort Study. Journal of the American College of Cardiology. 2014;64:2222-31.

53. Pathak RK, Middeldorp ME, Meredith M, Mehta AB, Mahajan R, Wong CX, Twomey D, Elliott $A D$, Kalman JM, Abhayaratna WP, Lau DH and Sanders P. Long-Term Effect of Goal-Directed Weight Management in an Atrial Fibrillation Cohort: A Long-Term Follow-Up Study (LEGACY). Journal of the American College of Cardiology. 2015;65:2159-69.

54. Hatem SN and Sanders P. Epicardial adipose tissue and atrial fibrillation. Cardiovascular research. 2014;102:205-13.

55. Wong CX, Ganesan AN and Selvanayagam JB. Epicardial fat and atrial fibrillation: current evidence, potential mechanisms, clinical implications, and future directions. European heart journal. 2017;38:1294-1302.

56. Lauer MS, Anderson KM, Kannel WB and Levy D. The impact of obesity on left ventricular mass and geometry. The Framingham Heart Study. JAMA : the journal of the American Medical Association. 1991;266:231-6.

57. Rider OJ, Francis JM, Ali MK, Holloway C, Pegg T, Robson MD, Tyler D, Byrne J, Clarke K and Neubauer S. Effects of catecholamine stress on diastolic function and myocardial energetics in obesity. Circulation. 2012;125:1511-9.

58. Wyse DG, Waldo AL, DiMarco JP, Domanski MJ, Rosenberg Y, Schron EB, Kellen JC, Greene HL, Mickel MC, Dalquist JE, Corley SD and Atrial Fibrillation Follow-up Investigation of Rhythm Management I. A comparison of rate control and rhythm control in patients with atrial fibrillation. The New England journal of medicine. 2002;347:1825-33.

59. Van Gelder IC, Hagens VE, Bosker HA, Kingma JH, Kamp O, Kingma T, Said SA, Darmanata JI, Timmermans AJ, Tijssen JG, Crijns HJ and Rate Control versus Electrical Cardioversion for Persistent Atrial Fibrillation Study G. A comparison of rate control and rhythm control in patients with recurrent persistent atrial fibrillation. The New England journal of medicine. 2002;347:1834-40. 60. Packer DL, Mark DB, Robb RA, Monahan KH, Bahnson TD, Poole JE, Noseworthy PA, Rosenberg YD, Jeffries N, Mitchell LB, Flaker GC, Pokushalov E, Romanov A, Bunch TJ, Noelker G, Ardashev A, Revishvili A, Wilber DJ, Cappato R, Kuck KH, Hindricks G, Davies DW, Kowey PR, Naccarelli GV, Reiffel JA, Piccini JP, Silverstein AP, AI-Khalidi HR, Lee KL and Investigators C. Effect of Catheter Ablation vs Antiarrhythmic Drug Therapy on Mortality, Stroke, Bleeding, and Cardiac Arrest Among Patients With Atrial Fibrillation: The CABANA Randomized Clinical Trial. JAMA : the journal of the American Medical Association. 2019.

61. Kirchhof $P$, Benussi S, Kotecha D, Ahlsson A, Atar D, Casadei B, Castella M, Diener HC, Heidbuchel $H$, Hendriks J, Hindricks G, Manolis AS, Oldgren J, Popescu BA, Schotten U, Van Putte B, Vardas P, Agewall S, Camm J, Baron Esquivias G, Budts W, Carerj S, Casselman F, Coca A, De Caterina R, Deftereos S, Dobrev D, Ferro JM, Filippatos G, Fitzsimons D, Gorenek B, Guenoun M, Hohnloser SH, Kolh P, Lip GY, Manolis A, McMurray J, Ponikowski P, Rosenhek R, Ruschitzka F, Savelieva I, Sharma S, Suwalski P, Tamargo JL, Taylor CJ, Van Gelder IC, Voors AA, Windecker S, Zamorano JL and 
1 Zeppenfeld K. 2016 ESC Guidelines for the management of atrial fibrillation developed in collaboration with EACTS. European heart journal. 2016;37:2893-2962.

62. Mark DB, Anstrom KJ, Sheng S, Piccini JP, Baloch KN, Monahan KH, Daniels MR, Bahnson TD, Poole JE, Rosenberg Y, Lee KL, Packer DL and Investigators C. Effect of Catheter Ablation vs Medical Therapy on Quality of Life Among Patients With Atrial Fibrillation: The CABANA Randomized Clinical Trial. JAMA : the journal of the American Medical Association. 2019.

63. Blomstrom-Lundqvist C, Gizurarson S, Schwieler J, Jensen SM, Bergfeldt L, Kenneback G, Rubulis A, Malmborg H, Raatikainen P, Lonnerholm S, Hoglund N and Mortsell D. Effect of Catheter Ablation vs Antiarrhythmic Medication on Quality of Life in Patients With Atrial Fibrillation: The CAPTAF Randomized Clinical Trial. JAMA : the journal of the American Medical Association. 2019;321:1059-1068.

64. Marrouche NF, Brachmann J, Andresen D, Siebels J, Boersma L, Jordaens L, Merkely B, Pokushalov E, Sanders P, Proff J, Schunkert H, Christ H, Vogt J, Bansch D and Investigators C-A. Catheter Ablation for Atrial Fibrillation with Heart Failure. The New England journal of medicine. 2018;378:417-427.

65. Turagam MK, Garg J, Whang W, Sartori S, Koruth JS, Miller MA, Langan N, Sofi A, Gomes A, Choudry S, Dukkipati SR and Reddy VY. Catheter Ablation of Atrial Fibrillation in Patients With Heart Failure: A Meta-analysis of Randomized Controlled Trials. Annals of internal medicine. 2018. 66. Verma A, Jiang CY, Betts TR, Chen J, Deisenhofer I, Mantovan R, Macle L, Morillo CA, Haverkamp W, Weerasooriya R, Albenque JP, Nardi S, Menardi E, Novak P, Sanders P and Investigators SAI. Approaches to catheter ablation for persistent atrial fibrillation. The New England journal of medicine. 2015;372:1812-22.

67. De With RR, Rienstra M, Smit MD, Weijs B, Zwartkruis VW, Hobbelt AH, Alings M, Tijssen JGP, Brugemann J, Geelhoed B, Hillege HL, Tukkie R, Hemels ME, Tieleman RG, Ranchor AV, Van Veldhuisen DJ, Crijns H and Van Gelder IC. Targeted therapy of underlying conditions improves quality of life in patients with persistent atrial fibrillation: results of the RACE 3 study. Europace. 2019;21:563-571.

68. Pathak RK, Elliott A, Middeldorp ME, Meredith M, Mehta AB, Mahajan R, Hendriks JM, Twomey D, Kalman JM, Abhayaratna WP, Lau DH and Sanders P. Impact of CARDIOrespiratory FITness on Arrhythmia Recurrence in Obese Individuals With Atrial Fibrillation: The CARDIO-FIT Study. Journal of the American College of Cardiology. 2015;66:985-96.

69. Dobrev D and Nattel S. New antiarrhythmic drugs for treatment of atrial fibrillation. Lancet. 2010;375:1212-23.

70. Delgado V, Di Biase L, Leung M, Romero J, Tops LF, Casadei B, Marrouche N and Bax JJ. Structure and Function of the Left Atrium and Left Atrial Appendage: AF and Stroke Implications. Journal of the American College of Cardiology. 2017;70:3157-3172. 